\title{
Footprint of Inexhaustible Energy Usage and Financial Development on Carbon Outrush of Eurasian Countries
}

\author{
Ph.D. Candidate Daberechi Chikezie Ekwueme (Eastern Mediterranean University, TR of \\ Northern Cyprus)
}

\begin{abstract}
Climate change has a menacing influence on the life and health of human beings; and environmental hallmarks for the future cohort. Carbon outrush has been attributed as the fundamental cause of global warming and change in the climate. In the retardation of carbon effusion, reciprocation between financial development and the utilization of clean energy have been revealed by empirical literature to perform a vital function. Thus, this study analyzed the footprint of inexhaustible (clean) energy usage and financial development on $\mathrm{CO}_{2}$ outrush of 10 Eurasian countries utilizing the PMG-ARDL (Pooled Mean Autoregressive distributive lag model) from 1990 to 2017. Yearly Panel data was collected from the 2019 version of the World Development Indicator of the World Bank. The output of the analysis revealed that clean energy has a negative substantial footprint on the $\mathrm{CO}_{2}$ outrush while financial development has a positive substantial footprint on carbon outrush in the Eurasian countries under study. This output implies that the hallmark of the Eurasian countries' environment has greatly improved by utilizing clean energy and this has enhanced economic buoyancy. Therefore, we recommended that governments and policymakers in Eurasian countries in addition to enhancing the utilization of clean etymology of energy by firms and individual households should expedite the establishment of financial policies and funding that are ecofriendly.
\end{abstract}

\section{Introduction}

Climate change has a menacing influence on the life and health of human beings; and the environmental hallmark for future cohort, carbon outrush has been attributed as the fundamental cause of global warming. In the retardation of carbon effusion, reciprocation between financial development and the utilization of clean energy have been revealed by empirical literature to perform a vital function.

An enlarging unanimity has materialized among environmental, energy, and scientific investigators concerning the menacing influence of global heating and variation in climate on the life and health of human beings; and the environmental hallmark for a future cohort over the previous few decagons (Zhang et.al, 2017). Enormous policymakers and scientific investigators have accentuated the notability of curtailing effusions from (GHG) greenhouse gas which has been attributed as the fundamental cause of global heating to eschew catastrophe in the environment globally. For example, according to Owusu \& Amsumadu Sarkodie, (2016) and Carbon Footprint, (2018), the thought of moderating the emission of carbon dioxide which has a greater percentage of the anthropogenic greenhouse gas amounting to about $81 \%$ has become the priority of the developed economies of the world.

This is further established by the White House (2016) that stated GHGs (Emissions of greenhouse gases) have been spotted to compose a higher proportion of the prime mover of climatic change and spotlighted that urgent attention geared towards abating effusion of carbon is a prerequisite to avert impending national security and growth in the economy in the remote future.

Thus, according to Charfeddine and Kahia (2019), concerning mitigation of effusions from GHG if no measures are taken, then these outcomes explicitly suggest that the average temperature globally will escalate to $2^{\circ} \mathrm{C}$ and if this escalating temperature threshold degree has transcended the influence on the life of humans and the ecosystem following the numerous environmental experts and environmental organizations stipulations will be very intense and will greatly upset all facets of life.

Transcending the threshold degree of $2^{\circ} \mathrm{C}$ will amount to the melting of the Arctic, reduction of freshwater and crops, intense hurricanes, wildfires escalation, super droughts, mass extinctions, and the swift increase in seas levels according to the current statement on Climate and Health by the Medical Society Consortium. Li and $\mathrm{Wu}$ (2017) further buttressed that it will also result in an escalation of health problems, water pollution, and mitigation in the quality of food and air.

Enormous studies in the literature of environment experimentally discovered that the alteration in the climate is primarily ascribed to the expeditious escalation in the greenhouse gas effusions from nitrous oxide, methane gas, and carbon dioxide (Belaid and Youssef 2017, Ozokcu and Ozdemir, 2017, Ekwueme and Zoaka, 2020). Numerous additional studies have stated that the majority of the endeavors (for instance the United Nations Framework Conventions on Climate Change and the Kyoto protocol) are not adequate to tackle the challenges posed by alteration in climate (Charfeddine and Kahia (2019). Consequently, ratification of ultra-modern economic policies, laws, and regulations has been suggested by numerous scholars and researchers as a tool that will enhance the quality of the ecosystem (Cardenas et al., 2016 and Zhang and Wang 2017). 
Nevertheless, a handful of more studies have revealed that reduction in the growth of the economy can emanate from enhancing the standard of the environment through the policies of conservation of energy (Destek and Aslan 2017 and Chen et al., 2016). Therefore, those involved in policymaking are faced with the primary obstacle of maintaining an equilibrium between having sustainable economic growth and mitigation of environmental deterioration objectives (Kahia et al. 2017 and Charfeddine et al., 2016). Policymakers thus are confronted to construct constant and low-priced energy origins accessible simultaneously with mitigating effusions from GHG.

Various vital policy alternatives have been proposed from the pragmatic standpoint to provide a superior blueprint environmentally that can mitigate the accelerating rate of carbon effusions. Three postulations from the viewpoint of economic, energy, and environment are of major curiosity and they are clean energy advancement, financial sector advancement, and the scrutinizations of the links between clean energy usage and financial enlargement (development) on economic growth and $\mathrm{CO}_{2}$ outrush. The first postulation comprised of advancing the origin of clean energy and consequently mitigating substantially carbon effusions and other forms of pollutants. Enormous empirical researches have proved that the advancement of the financial sector by promoting the advancement of technology in the energy sector can perform an essential function in carbon effusions mitigation. Further, concerning the third postulation, empirical research has provided evidence of linkages between usage of clean energy, and financial development and mitigation of effusions from carbon (Abbas and Riaz, 2016 and Charfeddine and Kahia 2019). Charfeddine and Kahia 2019 revealed that the credit markets and commercial banking can perform a vital function of invigorating and advancing the inexhaustible energy sector. This is further buttressed by Kim and Park (2016) who revealed that the reliance of clean sections (sectors) on funding from the capital market has resulted in a spontaneous unequal escalation in nations with advanced financial markets.

Thus, this study attempts to investigate the footprint of inexhaustible (clean) energy usage and financial development on the $\mathrm{CO}_{2}$ outrush of 12 Eurasian countries utilizing the PMG-ARDL (Pooled Mean Autoregressive distributive lag model) from 1990 to 2017. Prior research from the standpoint of literature has explored the footprint of clean energy and financial development on carbon outrush adopted univariate category of model employing either panel data or time-series data approach. Additionally, only a handful of research has examined these variables together in one equation. In Eurasian countries, there is no empirical literature to the best of our knowledge that has examined the footprint of clean energy usage and financial development on $\mathrm{CO}_{2}$ outrush in a multivariate panel taking into account both variables (clean energy and financial development) exclusively in one regression. This study, therefore, filled the above-identified gap by employing the multivariate PMG-ARDL (Pooled Mean Autoregressive distributive lag model) mode to scrutinize the footprint of inexhaustible (clean) energy usage and financial development on $\mathrm{CO}_{2}$ outrush.

This research will enhance the literature of environment and energy in the Eurasian countries concerning the footprint of inexhaustible (clean) energy usage and financial development on $\mathrm{CO}_{2}$ outrush. The Eurasian countries were sampled because the majority of the countries are vastly energy exhaustive, possess a large capacity of financial resources, and exhibit an enormous ability to produce energy from clean sources like wind and solar.

Finally, the study provides many policy implications geared towards enhancing the footprints of clean energy and financial development on the outrush of $\mathrm{CO}_{2}$. The contributions from the research will help the policymakers to know the connection between these variables and the vital function it performs in the sustainable development of the countries, and the need to establish policies, procedures, and strong institutions that will facilitate the transition to clean energy sources.

The study's remaining parts are structured as follows: Section 2 comprises of literature review; data and methodology are contained in section 3; section 4 comprises of outcomes (results) and the methodology; deductions (conclusions) and the policy inferences (implications) of the study are found in section 5.

\section{Literature Review}

Prior literature as regards the footprint of financial development and clean energy usage was reviewed in this part of the study. For the prior two decagons, there had been an energetic discourse regarding the swift advancement of clean energy usage and its influence on the outrush of $\mathrm{CO}_{2}$ ( Shabbaz et al. 2017, Al-Mulali et al., 2015, Moutinho and Robaina 2016, Kahia et al., 2017, and Kahia et al 2016). It is a well-known fact from the viewpoint of climate alteration that the utilization of clean energy has a positive footprint on the quality of the environment by mitigating the rate of outrushing from greenhouse gas in the air (Boluk and Mert. 2014 and Bhattacharya et al. 2016, Bekun et al 2019).

Additionally, investing in sources that produce clean energy according to the 2018 report of OECD have been observed to be slighter carbon exhaustive, unlike unclean energy. Therefore, nations will evolve an international green and clean ecosystem scheme and enhance the standard of the environment by adopting sources that generate clean energy.

Nevertheless, from the viewpoint of the economic, evolvement of clean energy origins presents numerous energy and economic advantages (Dai et al., 2016 and Spiegel-Feld et al., 2016). According to Mu et al., (2018) and Ortega-Izquierdo et al. (2016), the economic advantages of adopting clean energy sources are providing solutions 
to numerous problems like unemployment, the outflow of foreign currency, energy mix portfolio diversification, and energy security to mention but a few, this is because, in comparison to the unclean energy sector, the clean energy sector uses more labor. Reliance of oil-importing nations on foreign oil will be mitigated by investment in clean energy, on the other hand, it will promote diversification of economy and shift of technology together with maintenance of earnings from the export of hydrocarbon for oil-exporting nations (Kahia et al., 2017 and Kahia et al., 2016).

Broadly, the outcomes from the empirical literature are conflicting and appear to rely on the techniques of econometrics adopted, type of data (panel or time series data), the duration of the study, and the economic features of the sampled countries.

Numerous studies discovered two-way causal linkages between clean energy and outrush of carbon, For example, Al-Mulali et al. (2015) examined this for the Caribbean and Latin America nations; Moutinho and Robaina (2016) examined this for twenty European countries; Apergis and Payne (2015) examined this for seven Central American nations; while Charfeddine and Kahia (2019) examined this for countries in the MENA region . On the other hand, the uni-directional causal link between clean energy, economic growth, and carbon outrush was supported by some empirical literature for example (Sardorsky, 2009 examined this for G7 countries).

Furthermore, clean energy usage was found to have a positive influence on the standard of the environment and enhances sustainable growth in the economy by some studies such as Bhattacharya et al. (2016) who examined this for eighty-five developing and developed nations using the system GMM and FMOLS model; Ito (2017) who examined this for forty-five developing nations using the GMM and Pooled Mean Group techniques; and Boluk and Mert (2014) who examined this for sixteen EU nations adopting the panel fixed-effect model. Contrarily, only a handful of studies discovered that a negative impact of clean energy usage on economic growth, for example, Silva et al. (2012) found this for Spain, Denmark, and Portugal.

Sinha and Shabbaz (2018) scrutinized the hypothesis of EKC for emissions of carbon dioxide in India from 1971 to 2015 utilizing the ARDL technique and revealed that the hypothesis exists for India with an inverted U-shape, also they discovered renewable energy usage and trade mitigates effusions of carbon in both the long-run and short-run, although it is effect is more in the long-run.

Dong et al (2018) examining the hypothesis of EKC against carbon effusions in China from 1965 to 2016 affirms that the hypothesis exists for China concerning effusions of carbon. Further, they discovered that in both the shortrun and long-run that natural gas and renewable energy reduces the effusion of carbon dioxide, nevertheless, in the remote future (long-run) the ability of natural gas to mitigate carbon effusions will be weakened but that of renewables will be constantly progressing in terms of reduction in carbon emissions.

Regarding the influence of financial development on the outrush of carbon, there is a solid concurrence theoretically, among scholars concerning the vital function performed by financial development in the stimulation of growth in the economy (Charfeddine and Kahia (2019). Presently, there is no wavering that developing the financial sector is a requisite pile for growth in the economy since it provides optimal allocation of capital, the amassment of capital via mobilization and fusing of savings, and enhancing the needed information for investment activities. By promoting the advancement of technology in the energy supply sector, the financial sector according to Kim and Park (2016), performs an essential function in monitoring effusions from energy. This proves that the development of the financial sector which reveals the actual financial resource available for manufacturing activities and financing mechanism for investments by stock markets and banks can perform an essential function in the strive against degradation of the environment through mitigation of carbon outrush (Charfeddine et al. 2018).

According to Hayat et al. (2018), development of the financial sector can normally start with R\&D (research and development) programs, allure FDI (foreign direct investment), and consequently, accelerate economic activities to affect the environmental standard through investments in green-related projects. Also, Charfeddine (2017) stated that an efficiently advanced financial sector can enhance the energy sector efficiency by impeding the energy outrush spread, mitigating the cost of borrowing, and promoting green investment activities.

Ekwueme and Zoaka (2020) employing fully modified ordinary least square in the study on the links between financial development, energy usage, openness in trade, growth economically, and C02 effusions in the MENA region revealed that financial development had a negative inference on the effusions of carbon, thus it enhances the quality of the environment.

Furthermore, financial development was discovered by Dogan and Seker (2016) to result in substantial mitigation in effusions of carbon in twenty-three (23) countries that use renewable energy.

Nevertheless, the development of the financial sector can degrade the quality of the environment by accelerating production activities, resulting in a rise in the rate of pollution and environmental deterioration (Nassani et al 2017). Nassani et al (2017) found that for countries in BRICS the emission of Nitrous oxide accelerates with financial development. Similarly, in Malaysia, carbon effusions from the gas and transport sector were discovered by Maji et al. (2017) to be enhanced by financial development, while financial development mitigates effusions from the construction and manufacturing sectors. 
Also, Kwakwa et al. (2018) examined the linkages between natural resources extraction and financial development within the framework of the hypothesis of EKC in Tunisia from1971 - 2016 and discovered that total effusion from carbon is enhanced by financial development.

Thus, there is no agreement among investigators empirically concerning the influence of financial development on carbon outrush. However, theoretically, there is a harmony that financial development and clean energy have a positive influence on economic growth and the standard of the environment, nevertheless prior empirical research finds it difficult to arrive at this agreement. Therefore, we employed the PMG-ARDL (Pooled Mean Autoregressive distributive lag model) econometric approach to contribute to this literature.

\section{Research Methodology}

\subsection{Description of Data}

Yearly Panel data was collected from the 2019 version of the World Development Indicator of the World Bank from 1990 to 2017 for 10 Eurasian countries; Armenia, Moldova, Azerbaijan, Russia Federation, Belarus, Tajikistan, Georgia, Ukraine, Kyrgyzstan, and Kazakhstan. The panel model was used because nations diverge in disparate facets and to control for heterogeneity differences. Table 1 below summarizes the variables employed in this study, their symbols, their predicted sign on $\mathrm{CO}_{2}$ outrush, and their proxies. To reduce heteroscedasticity and non-normality, the entire variables were expressed in natural logarithm form.

\begin{tabular}{lll}
\hline Symbols & Variables & Proxy \\
\hline GDPT $(+)$ & Economic growth & constant 2010 US \$) Gross domestic product \\
TRDE & Trade openness & \{percentage of GDP \} sum of imports and exports \\
RENR(-) & Renewable energy use & $\%$ of total final energy use \\
FD $(+)$ & Financial development & (\% of GDP) Domestic credit to privates \\
CO2E & Carbon outrush & Metric per tons per capital \\
\hline
\end{tabular}

Table 1: List of Variables Used and Their Proxy

\subsection{Specification of Model.}

The footprint of clean energy, economic growth, financial development, and trade openness on $\mathrm{CO}_{2}$ outrush was modeled on the EKC hypothesis theoretically, and empirically by extending the model utilized by to Charfeddine and Kahia (2019) and Nguyen and Kakinaka, (2019). Nevertheless, our model is unique as it included financial development variables in one regression equation in contrast to the above-mentioned works. Therefore, our model is stated below:

Co $2 E i_{t}=\alpha+\partial X i_{t}+\varepsilon i_{t}$

Where $\mathrm{CO} 2 \mathrm{E}$ denotes carbon outrush and is the dependent variable, $\mathrm{i}$ denotes sampled nations, $\mathrm{t}$ denotes years (time), and X represents the regressors (namely: clean energy usage, financial development, economic growth, and openness in trade). Eis the country-specific impact that cannot be observed.

\subsection{Econometric Techniques}

Many econometrics techniques were utilized in establishing the linkages between financial stability, $\mathrm{CO}_{2}$ outrush, and monetary policy. Firstly, the stationarity of the data was determined using the IPS $2003 \mathrm{of} I \mathrm{~m}$, Pesaran and Shin, LLC (Levin-Lin-Chu, 2002), PP (Philips-Perron) by Philip and Xiao (1998), and the Augmented DickeyFuller (F-ADF) unit root test. Secondly, Kao residual Cointegration test was carried out to ascertain if the variables are related in the long run. Then, the PMG-ARDL (Pooled Mean Autoregressive distributive lag model) will be estimated to assess the dynamic association between the various variables employed in the study. The traditional estimation models of Autoregressive distributive lag model (ARDL) is incapacitated to check for intolerance (bias) associated with the correlation between the white noise term and the mean differenced explanatory variable particularly in panel data exhibiting individual influences (effects), therefore, the ARDL model was combined with PMG estimator by Pesaran et al. (1999) to offer a solution to the problem. The Pooled Mean Autoregressive distributive lag model employed by Sarkodie and Strezov (2018) was applied in this study.

\section{Results and Discussions}

The outcomes of the analysis are presented and discussed in this section. 


\subsection{Descriptive Statistics}

\begin{tabular}{lllcll}
\hline Statistics & LNCO2EM & LNFD & LNRENR & LNGDPT & LNTRDE \\
\hline Mean & 1.02 & 2.69 & 1.91 & 23.83 & 4.50 \\
Median & 1.26 & 2.74 & 1.71 & 23.22 & 4.51 \\
Maximum & 2.75 & 4.50 & 4.16 & 28.15 & 5.16 \\
Minimum & -1.22 & 0.15 & -0.50 & 21.55 & 3.82 \\
Standard deviation & 1.08 & 0.89 & 1.28 & 1.70 & 0.30 \\
\hline
\end{tabular}

Table 2: Summary of Descriptive Statistics
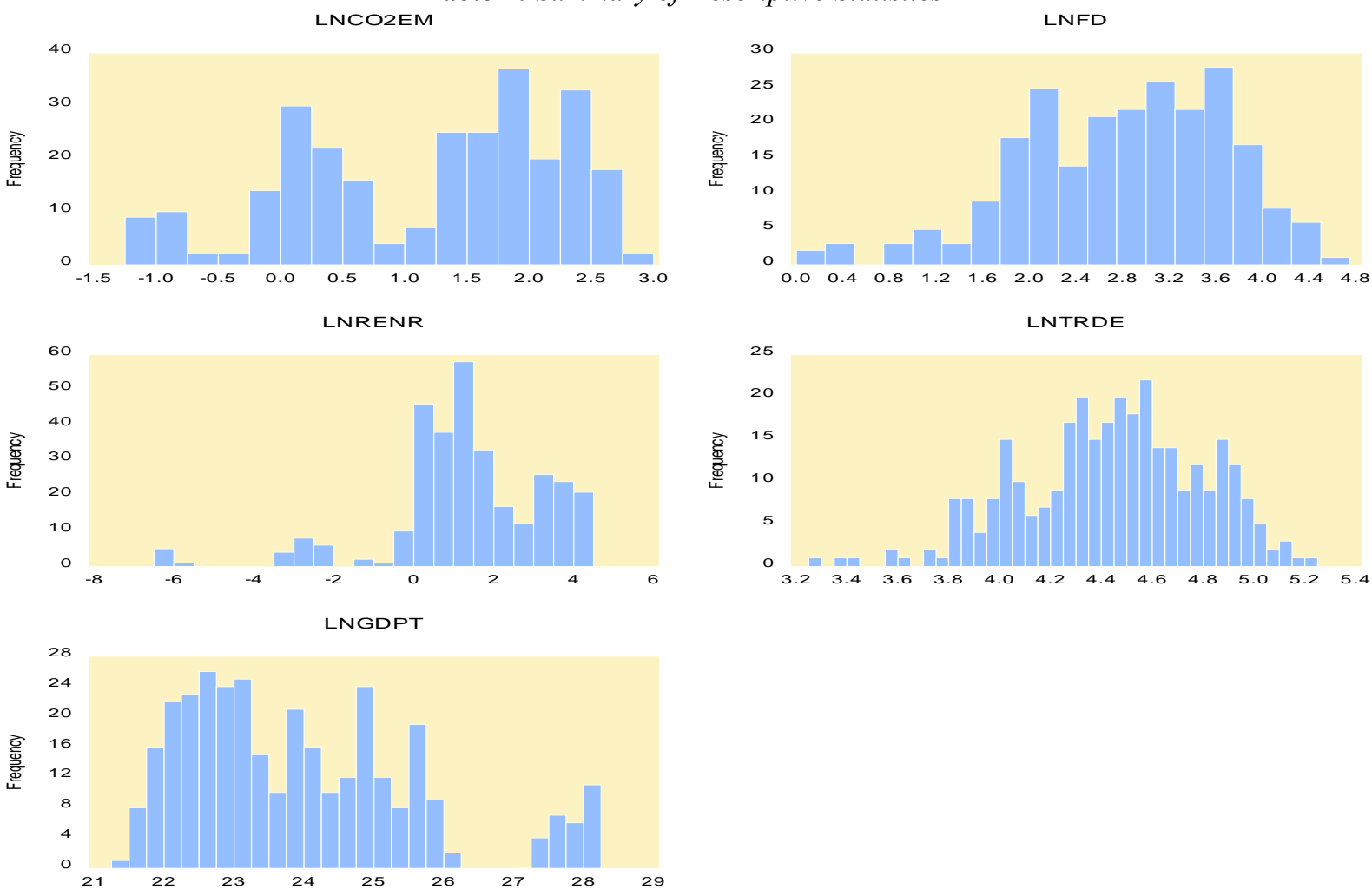

Fig. 1 Movement Pattern of Financial Development (FD), Renewable Energy Use (RENR), Economic Growth (GDPT), TRDE (trade openness), and CO2EM (carbon emissions

\begin{tabular}{|c|c|c|c|c|c|}
\hline Correlation & LNCO2EM & LNFD & LNRENR & LNTRD & LNGDPT \\
\hline LNCO2EM & 1.0000 & & & & \\
\hline T_Statistic & $\ldots \ldots$ & & & & \\
\hline Prob_V. & ....... & & & & \\
\hline LNFD & 0.3657 & 1.0000 & & & \\
\hline T_Statistic & 5.5719 & $\ldots \ldots$ & & & \\
\hline Prob_V. & $0.0000 *$ & $\ldots \ldots$ & & & \\
\hline LNRĒER & -0.5815 & -0.2133 & 1.0000 & & \\
\hline T_Statistic & -10.1339 & -3.096 & $\ldots \ldots$ & & \\
\hline Prob_V. & $0.0000 *$ & $0.0022 *$ & $\ldots \ldots$ & & \\
\hline LNTR̄DE & -0.2765 & -0.0721 & 0.0920 & 1.0000 & \\
\hline T_Statistic & -4.0805 & -1.0258 & 1.3102 & $\ldots \ldots$ & \\
\hline Prob_V. & $0.0001 *$ & 0.3062 & 0.1916 & $\ldots \ldots$ & \\
\hline LNGDיPT & 0.5555 & 0.3124 & -0.2235 & -0.4243 & 1.0000 \\
\hline T_Statistic & 9.4641 & 4.6632 & -3.2518 & -6.6445 & $\ldots \ldots$ \\
\hline Prob_V. & $0.0000 *$ & $0.0000 *$ & $0.0013 *$ & 0.0000 & $\ldots \ldots$ \\
\hline
\end{tabular}

* "represents statistical rejection at $0.05 \%$ significance level

Table 3: Results of the Correlation Coefficient Matrix

Table 1 is the presentation of the descriptive statistics of LNCO2EM (carbon outrush), LNFD (financial development), LNRENR (clean energy use), LNGDPT (economic growth), and LNTRDE (Trade). The mean of LNFD is very small in comparison to other developing and developed economies. The fluctuations in the level of financial development are shown by the maximum and minimum values of 2.75 and -1.22 respectively. This means that the financial development of Eurasian countries was relatively low in comparison to other regions in the world. The clean energy use (LNRENR) mean of 1.91 is also relatively small and the variability in the level of the clean 
energy use (LNRENR) is exhibited by the maximum value and the minimum value of 4.16 and -0.50 respectively. The mean, maximum, and minimum values of the LNGDPT, LNCO2EM, and LNTRDE suggest a small variation over time.

The correlation matrix output in Table 3 displays the associations among the series which is in accordant with the laid down theories of economics. For instance, financial development and GDP is anticipated to have a positive correlation with the outrush of carbon. While clean energy use is anticipated to have a negative relationship with carbon outrush.

\subsection{Unit Root Test}

Employing LLC, IPS, PP (Philips-Perron), and the Augmented Dickey-Fuller (F-ADF) unit root test the study determined the stationarity of the variables under study. The Schwarz Information Criterion (SIC) was observed utilizing the lag length.

\begin{tabular}{|c|c|c|c|c|c|}
\hline Methods & LNCO2EM & LNFD & LNRENR & LNGDPT & LNTRDE \\
\hline \multicolumn{6}{|l|}{ LLC_t-stat* } \\
\hline Level & $-7.7390 *$ & -0.1219 & $-9.0684 *$ & 0.8561 & $-3.3259 *$ \\
\hline First difference & & $-8.3212 *$ & & $-4.6200 * \%$ & \\
\hline \multicolumn{6}{|l|}{ IPS-W-stat } \\
\hline Level & $-5.4688 *$ & -0.1 .2625 & $-5.4457 *$ & 3.4511 & $-4.7570 *$ \\
\hline First difference & & $-10.1115^{*}$ & & $-4.1684 *$ & \\
\hline \multicolumn{6}{|c|}{ ADF-Fisher Chi-sq. } \\
\hline Level & $85.3662 *$ & 39.8993 & $82.3469 *$ & 12.6183 & $80.2526^{*}$ \\
\hline First difference & & $122.345^{*}$ & & $56.5351 *$ & \\
\hline \multicolumn{6}{|c|}{ PP-Fisher Chi-sq. } \\
\hline Level & $63.8433 *$ & 44.0866 & $60.175^{*}$ & 6.9829 & $54.4658 *$ \\
\hline First difference & & $136.669 *$ & & $47.1629 *$ & \\
\hline
\end{tabular}

Notes: * implies the rejection of null hypothesis at $0.05 \%$ level of significance. For the entire test probabilities calculated asymptotic normality is assumed. The numbers are the t.statistic of the individual test.

\section{Table 4: Results of Panel Unit Root Test}

The outcome of Table 4 above reveals that at level three series (LNCO2EM, LNRENR, and LNTRDE are stationary, while two series (LNFD and LNGDPT) are stationary at the first difference at $0.05 \%$ significance level in all the tests. Therefore, based on the results we deduced that LNCO2EM, LNRENR, and LNTRDE are I (0) series, while LNFD and LNGDPT are I (1) series, as they become stationary at first difference. Hence, we moved to Kao residual cointegration test.

\subsection{The outcome of Kao Residual Cointegration Test}

\begin{tabular}{lll}
\hline ADF & t. Statistics & Prob.value \\
\hline & -4.0421 & $0.0000^{*}$ \\
\hline Residual variance & 0.0126 & \\
HHAC variance & 0.0127 & \\
\hline
\end{tabular}

Table 5: Results of Kao Residual Cointegration Test

The hypothesis of no cointegration among the series was rejected at $0.05 \%$ significance level by the Kao residual cointegration in Table 5 above, thus we concluded that the entire variables under study are related in the long-run.

\subsection{The outcome of PMG-ARDL (Pooled Mean Autoregressive Distributive Lag Model)}

Having determined that the series are not integrated of the same order, we proceeded to estimate the PMGARDL to ascertain the enormity of the cointegration is displayed in Table 6. 


\begin{tabular}{lcccc}
\hline Variables & coefficient & Std.Error & t-statistics & Prob.value \\
\hline \multicolumn{5}{c}{ Long Run Equation } \\
\hline LNFD & 0.0914 & 0.0116 & 7.8390 & $0.0000^{*}$ \\
LNRENR & -0.4329 & 0.0202 & -21.3526 & $0.0000^{*}$ \\
LNTRDE & 0.2534 & 0.0703 & 3.6033 & $0.0005^{*}$ \\
LNGDPT & 0.3814 & 0.0250 & 15.2415 & $0.0000^{*}$ \\
\hline \multicolumn{5}{c}{ Short Run Equation } \\
\hline ECT(-1) & -0.6003 & 0.1230 & -4.8769 & $0.0000^{*}$ \\
LNFD & 0.0395 & 0.0440 & 0.8967 & 0.3723 \\
LNRENR & -0.1090 & 0.1734 & -0.6285 & 0.5313 \\
LNGDPT & 0.1769 & 0.4098 & 0.4316 & 0.6670 \\
LNTRDE & -0.0513 & 0.1435 & -1.5148 & 0.7212 \\
\hline
\end{tabular}

Note $* *$ and $*$ means statistically significant at $0.10 \%$ and $0.05 \%$ respectively. Akaike info criterion is the model selection method which suggested lag 2 and the most parsimonious.

Table 6: Outcome of PMG-ARDL (2, 2, 2, 2, 2)

The outcome in Table 6 reveals that a significant positive correlation between LNFD (financial development), LNTRDE (openness in trade), LNGDPT (economic growth), and $\mathrm{CO}_{2}$ outrush in the long-run in the sampled Eurasian countries. This suggests that a $1 \%$ increase in the development of the financial sector, trade openness, and economic activities will amount to $0.09 \%, 0.25 \%$, and $0.38 \%$ increase in $\mathrm{CO}_{2}$ outrush respectively. This is accordant with the scale influence (effect); therefore this research supports a positive correlation between growth in the economy and deterioration of the environment (Alola and Alola, 2018 and Ito, 2017). This discovery is an indicator of policymakers and environmental managers in these countries on the urgency to mitigate $\mathrm{CO}_{2}$ outrush. Concerning clean or inexhaustible energy usage, a significant negative correlation was discovered between LNRENR (clean energy use) and $\mathrm{CO}_{2}$ outrush in the long-run, this suggests that a $1 \%$ increase in clean energy use will amount to a $0.43 \%$ reduction in $\mathrm{CO}_{2}$ outrush in the sampled Eurasian countries. This outcome is accordant with Charfeddine and Kahia (2019) and Nguyen and Kakinaka, (2019), and it is interesting to environmental and energy economists. This outcome is creditable and could be attributable to the fact that the majority of the Eurasian nations are endorsers of the Kyoto protocol agreement aimed at mitigating $\mathrm{CO} 2$ outrush.

Furthermore, the outcome reveals a robust computation with a speed of convergence of $6 \%$ by the contribution of other regressors towards the path of equilibrium. Nevertheless, in the short-run, there was a negative correlation between clean energy usage, openness in trade, and $\mathrm{CO}_{2}$ outrush, though it is not statistically significant. Also, an insignificant [positive relationship was found between economic growth and $\mathrm{CO} 2$ outrush in the sampled Eurasian countries. This result is accordant with Bekun et al, (2019) who discovered a positive insignificant positive correlation between growth in the economy and $\mathrm{CO}_{2}$ outrush in $16 \mathrm{EU}$ countries in the short-run.

The diagnostic test of confidence ellipse displayed in Fig. 2 below reveals that the points of stability are within the center of the ellipse, this suggests that a significant confidence level is exhibited in the model.

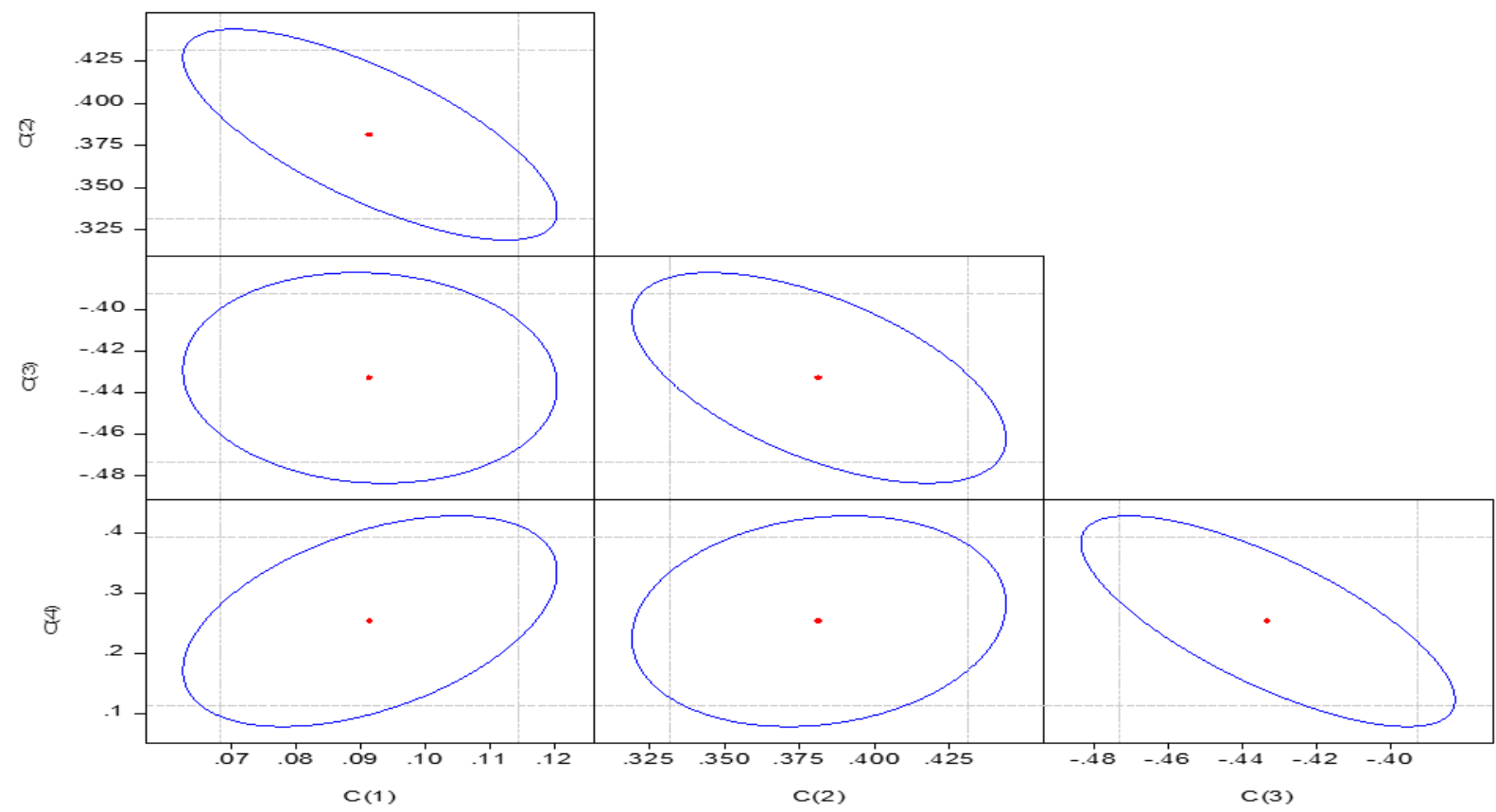

Fig 2: Coefficient Diagnostic Test with Confidence Interval 


\section{Conclusion}

Climate change has a menacing influence on the life and health of human beings; and environmental hallmarks for the future cohort. Carbon outrush has been attributed as the fundamental cause of global warming and change in the climate. In the retardation of carbon effusion, reciprocation between financial development and the utilization of clean energy have been revealed by empirical literature to perform a vital function. Thus, this study analyzed the footprint of inexhaustible (clean) energy usage and financial development on $\mathrm{CO}_{2}$ outrush of 10 Eurasian countries utilizing the PMG-ARDL (Pooled Mean Autoregressive distributive lag model) from 1990 to 2017.

The outcome of the analysis revealed a significant negative correlation between LNRENR (clean energy use) and $\mathrm{CO}_{2}$ outrush in the long-run, this suggests that the quality of the environment in Eurasian countries can be enhanced in the long-run by utilization of clean energy sources. This output implies that the hallmark of the Eurasian countries' environment has greatly improved by utilizing clean energy. This result can be attributed to the dedication of the countries in the Eurasian region to mitigating carbon outrush and promoting the utilization of clean etymology (origins) of energy by firms and individual households and the majority of the sampled countries are endorsers of the Kyoto protocol.

However, the results further reveal a significant positive correlation between LNFD (financial development), LNTRDE (openness in trade), LNGDPT (economic growth), and $\mathrm{CO}_{2}$ outrush in the long-run. This suggests that governments and policymakers of Eurasian countries should promote formulation and implementation of financial reforms aimed at encouraging $\mathrm{R} \& \mathrm{D}$ (research and development) for inventive mechanizations concerning clean energy such as solid waste, solar, hydro, biogas, and biomass. This will mitigate $\mathrm{CO}_{2}$ outrush and enhance a sustainable environment.

\section{References}

- Abbasi, F., \& Riaz, K. (2016). CO2 emissions and financial development in an emerging economy: an augmented VAR approach. Energy Policy, 90, 102-114.

- Al-Mulali, U., Saboori, B., \& Ozturk, I. (2015). Investigating the environmental Kuznets curve hypothesis in Vietnam. Energy Policy, 76, 123-131.

- $\quad$ Alola, A. A., \& Alola, U. V. (2018). Agricultural land usage and tourism impact on renewable energy consumption among Coastline Mediterranean Countries. Energy \& Environment, 29(8), 1438-1454.

- $\quad$ Apergis, N., Bowden, N., \& Payne, J. E. (2015). Downstream integration of natural gas prices across the US states Evidence from deregulation regime shifts. Energy Economics, 49, 82-92.

- $\quad$ Bekun, F. V., Alola, A. A., \& Sarkodie, S. A. (2019). Toward a sustainable environment: Nexus between $\mathrm{CO} 2$ emissions, resources rent, renewable and nonrenewable energy in 16-EU countries. Science of the Total Environment, 657, 1023-1029.

- $\quad$ Belaid, F., \& Youssef, M. (2017). Environmental degradation, renewable, and non-renewable electricity consumption, and economic growth: Assessing the evidence from Algeria. Energy Policy, 102, 277-287.

- Bhattacharya, M., Paramati, S. R., Ozturk, I., \& Bhattacharya, S. (2016). The effect of renewable energy consumption on economic growth: Evidence from top 38 countries. Applied Energy, 162, 733-741.

- Bölük, G., \& Mert, M. (2014). Fossil \& renewable energy consumption, GHGs (greenhouse gases) and economic growth: Evidence from a panel of EU (European Union) countries. Energy, 74, 439-446.

- Carbon Footprint, (2018). Climate change. Retrieved from. https://www.carbonfootprint.com/warming.html.

- Cardenas, L. M., Franco, C. J., \& Dyner, I. (2016). Assessing emissions-mitigation energy policy under integrated supply and demand analysis: the Colombian case. Journal of Cleaner Production, 112, 37593773 .

- Charfeddine, L. (2017). The impact of energy consumption and economic development on Ecological Footprint and CO2 emissions: Evidence from a Markov Switching Equilibrium Correction Model. Energy Economics, 65, 355-374.

- Charfeddine, L., \& Kahia, M. (2019). Impact of renewable energy consumption and financial development on $\mathrm{CO} 2$ emissions and economic growth in the MENA region: A panel vector autoregressive (PVAR) analysis. Renewable energy, 139, 198-213.

- Charfeddine, L., \& Khediri, K. B. (2016). Financial development and environmental quality in UAE: Cointegration with structural breaks. Renewable and Sustainable Energy Reviews, 55, 1322-1335.

- Charfeddine, L., Al-Malk, A. Y., \& Al Korbi, K. (2018). Is it possible to improve environmental quality without reducing economic growth: Evidence from the Qatar economy. Renewable and Sustainable Energy Reviews, 82, 25-39. 
- Chen, P. Y., Chen, S. T., Hsu, C. S., \& Chen, C. C. (2016). Modeling the global relationships among economic growth, energy consumption, and $\mathrm{CO} 2$ emissions. Renewable and Sustainable Energy Reviews, 65, 420-431.

- $\quad$ Dai, H., Xie, X., Xie, Y., Liu, J., \& Masui, T. (2016). Green growth: The economic impacts of large-scale renewable energy development in China. Applied energy, 162, 435-449.

- Destek, M. A., \& Aslan, A. (2017). Renewable and non-renewable energy consumption and economic growth in emerging economies: Evidence from bootstrap panel causality. Renewable Energy, 111, 757-763. Dong K., Sun R., \& Li H., et al. (2018) Does natural gas consumption mitigate CO2 emissions: Testing the environmental Kuznets curve hypothesis for 14 Asia-Pacific countries. Renew Sust Energy Rev 94: 419-429.

- $\quad$ Ekwueme, D. C., \& Zoaka, J. D. (2020). Effusions of carbon dioxide in MENA countries: inference of financial development, trade receptivity, and energy utilization. Environmental Science and Pollution Research, 1-12.

- Hayat, F., Pirzada, M. D. S., \& Khan, A. A. (2018). The validation of Granger causality through formulation and use of finance-growth-energy indexes. Renewable and Sustainable Energy Reviews, 81, 1859-1867.

- Im, K. S., Pesaran, M. H., \& Shin, Y. (2003). Testing for unit roots in heterogeneous panels. Journal of econometrics, 115(1), 53-74.

- Ito, K. (2017). CO2 emissions, renewable, and non-renewable energy consumption, and economic growth: Evidence from panel data for developing countries. International Economics, 151, 1-6.

- Kahia, M., Aïssa, M. S. B., \& Charfeddine, L. (2016). Impact of renewable and non-renewable energy consumption on economic growth: New evidence from the MENA Net Oil Exporting Countries (NOECs). Energy, 116, 102-115.

- Kahia, M., Aïssa, M. S. B., \& Lanouar, C. (2017). Renewable and non-renewable energy use-economic growth nexus: The case of MENA Net Oil Importing Countries. Renewable and Sustainable Energy Reviews, 71, 127-140.

- $\quad$ Kim, J., \& Park, K. (2016). Financial development and deployment of renewable energy technologies. Energy Economics, 59, 238-250.

- Kwakwa, A.P., Alhassan, H., \& Aboagye, S. (2018). Environmental Kuznets curve hypothesis in financial development and natural resource extraction context: evidence from Tunisia.

- Levin, A., Lin, C. F., \& Chu, C. S. J. (2002). Unit root tests in panel data: asymptotic and finite-sample properties. Journal of econometrics, 108(1), 1-24.

- $\quad$ Li, B., \& Wu, S. (2017). Effects of local and civil environmental regulation on green total factor productivity in China: A spatial Durbin econometric analysis. Journal of Cleaner Production, 153, 342-353.

- $\quad$ Maji I. K., Habibullah M. S., \& Saari M. Y. (2017) Financial development and sectoral CO2 emissions in Malaysia. Environ Sci Pollut Res 24: 7160-7176.

- Moutinho, V., \& Robaina, M. (2016). Is the share of renewable energy sources determining the CO2 kWh and income relation in electricity generation?. Renewable and Sustainable Energy Reviews, 65, 902-914.

- Mu, Y., Wang, C., \& Cai, W. (2018). The economic impact of China's INDC: Distinguishing the roles of renewable energy quota and the carbon market. Renewable and Sustainable Energy Reviews, 81, 2955-2966.

- Nassani A, A., Aldakhil A. M., \& Abro M. M. Q., et al. (2017) Environmental Kuznets curve among BRICS countries: spot lightening finance, transport, energy, and growth factors. J Clean Prod 154: 474-487

- $\quad$ Nguyen, K. H., \& Kakinaka, M. (2019). Renewable energy consumption, carbon emissions, and development stages: Some evidence from panel cointegration analysis. Renewable Energy, 132, 1049-1057.

- Ortega-Izquierdo, M., \& del Río, P. (2016). Benefits and costs of renewable electricity in Europe. Renewable and Sustainable Energy Reviews, 61, 372-383.

- Owusu, P., Asumadu, S.S., (2016). A review of renewable energy sources, sustainability issues, and climate change mitigation. Adv. Hum. Perform. Cogn. Eng. Res. 3, 1167990. https://doi.org/10.1080/23311916.2016.1167990

- $\quad$ Özokcu, S., \& Özdemir, Ö. (2017). Economic growth, energy, and environmental Kuznets curve. Renewable and Sustainable Energy Reviews, 72, 639-647.

- $\quad$ Pesaran, M. H., Shin, Y., \& Smith, R. P. (1999). Pooled mean group estimation of dynamic heterogeneous panels. Journal of the American Statistical Association, 94(446), 621-634.

- $\quad$ Phillips, P. C., \& Xiao, Z. (1998). A primer on unit root testing. Journal of Economic Surveys, 12(5), 423470 . 
- Sadorsky, P. (2009). Renewable energy consumption and income in emerging economies. Energy Policy, 37(10), 4021-4028.

- $\quad$ Sarkodie, S. A., \& Strezov, V. (2018). Empirical study of the environmental Kuznets curve and environmental sustainability curve hypothesis for Australia, China, Ghana, and USA. Journal of cleaner production, 201, 98-110.

- $\quad$ Shahbaz, M., Van Hoang, T. H., Mahalik, M. K., \& Roubaud, D. (2017). Energy consumption, financial development, and economic growth in India: New evidence from the nonlinear and asymmetric analysis. Energy Economics, 63, 199-212.

- Silva, S., Soares, I., \& Pinho, C. (2012). The impact of renewable energy sources on economic growth and CO2 emissions-a SVAR approach. European Research Studies, 15, 133.

- Sinha A., \& Shahbaz M. (2018) Estimation of Environmental Kuznets Curve for CO2 emission: Role of renewable energy generation in India. Renew Energy 119: 703-711.

- $\quad$ Spiegel-Feld, D., Rudyk, B., \& Philippidis, G. (2016). Allocating the economic benefits of renewable energy between stakeholders on Small Island Developing States (SIDS): Arguments for a balanced approach. Energy Policy, 98, 744-748.

- World Bank, (2019).World development indicators. Retrieved from. http://data.worldbank.org/country.

- Zhang, B., Wang, B., \& Wang, Z. (2017). Role of renewable energy and non-renewable energy consumption on EKC: evidence from Pakistan. Journal of Cleaner Production, 156, 855-864.

- Zhang, X., \& Wang, Y. (2017). How to reduce household carbon emissions: A review of experience and policy design considerations. Energy Policy, 102, 116-124. 